\title{
Jogos digitais e realidade virtual na Educação Infantil: Uma abordagem na Língua Inglesa
}

\author{
Nicole de Cássia Mesquita Teixeira ${ }^{1}$, Aline de Campos $^{2}$ \\ ${ }^{1}$ Prefeitura Municipal de Capivari do Sul e CINTED - Universidade Federal do Rio \\ Grande do Sul (UFRGS) - Porto Alegre - RS - Brasil \\ ${ }^{2}$ Programa de Pós-Graduação em Informática na Educação - Universidade Federal do \\ Rio Grande do Sul (UFRGS) - Porto Alegre - RS - Brasil \\ \{nicoledecassiat, alinedecampos\} gmail.com
}

\begin{abstract}
The insertion of a foreign language in early childhood education is still a growing challenge, due to the methodology to be used at this level of cognitive development. This article aims to report a qualitative research developed in a municipal school, with two Pre-I and Pre-II classes, totaling 28 students aged 5 to 6 years old, about an experience with digital games, with English language words. and the virtual reality glasses (VR-box). The results show that, in addition to the interaction between teacher and student, technological resources favored learning, promoting greater engagement among students.
\end{abstract}

Resumo. A inserção de uma língua estrangeira na Educação Infantil ainda é um crescente desafio, em virtude da metodologia a ser utilizada nesse nível de desenvolvimento cognitivo. Este artigo objetiva relatar uma pesquisa qualitativa desenvolvida, em uma escola municipal, com duas turmas do Pré-I e Pré-II, totalizando 28 alunos com idade entre 5 e 6 anos, acerca de uma experiência com jogos digitais, com palavras da Língua Inglesa e o óculos de realidade virtual (VR-box). Os resultados revelam que, além da interação entre professor e aluno, os recursos tecnológicos favoreceram a aprendizagem, promovendo um engajamento maior entre os estudantes.

\section{Introdução}

Observa-se que as crianças estão, cada vez mais cedo, conectadas à tecnologia pois vivem em meio às informações e às transformações. Além disso, estão dispostas às diferentes formas de aprendizagem, pois é na interação com o outro e com diferentes objetos de ensino que aprendem. Nesse sentido, os Jogos Digitais na Educação Infantil surgem e oportunizam aos professores a exploração das novas metodologias enquanto práticas pedagógicas.

Ao reconhecer a importância dos estímulos cognitivos no âmbito da aprendizagem, percebe-se que as crianças, em relação à aquisição linguística, têm a melhor capacidade de decodificação da língua materna, assim como da língua estrangeira. Esta é a melhor fase porque conseguem captar os sons, desenvolvendo o listening mais rápido. 
Portanto, a criança ao aprender um novo idioma, internaliza os conhecimentos linguísticos adquiridos pelo contato com a fala do adulto. Conhecer sobre as teorias Vygotskyanas é de suma importância. O autor se refere em seus estudos sobre o conceito de desenvolvimento proximal que ocorre quando o indivíduo desperta internamente os instrumentos que utilizam a inteligência, a capacidade de pensar, assim como as organizações psicológicas anteriores às da fala.

Segundo Vygotsky (2010), "uma correta organização da aprendizagem da criança conduz ao desenvolvimento mental, ativa todo um grupo de processos de desenvolvimento, e esta ativação não poderia produzir-se em aprendizagem" (p. 115). Além dessa interação, outro aspecto importante para o processo de ensino de línguas, é a relação afetiva entre aluno-professor, pois o desenvolvimento cognitivo também está ligado fortemente as emoções do indivíduo. A aprendizagem baseada em jogos permite que o estudante desenvolva suas habilidades intelectuais e cognitivas.

Segundo Krajden (2017) um jogo aborda desafios subjetivos aos envolvidos, isto é, possui intuito definido pelas normas, interação e feedback. Ainda segundo o autor demarcam problemas e oposições. Toda ação em um jogo necessita da disposição dos jogadores, mas no instante que decide jogar, as normas têm de ser analisadas.

Nesta perspectiva, surgiu a necessidade de analisar as TICs Tecnologia da Informação e Comunicação e o Ensino de Línguas, bem como, o Ensino do Inglês voltado ao uso de jogos digitais na educação. Para isso, a seção 3 descreve, especificamente, o método utilizado e o ambiente de aplicação, além da forma como os dados foram levantados e analisados. Já a seção 4 apresenta e discute a análise dos dados relativos às impressões dos alunos e da pesquisadora e, na última seção, sintetizam-se os principais pontos de análise relativos ao tema da investigação, trazendo, também, sugestões para futuros trabalhos.

\section{Procedimentos metodológicos}

A pesquisa caracterizou-se como estudo de caso com abordagem qualitativa, propondo-se analisar quais seriam os jogos e atividades online educativas infantis que cativassem e aproximassem os alunos da realidade adequados à sua faixa etária correta.

Para tanto, foram analisados diversos jogos educativos digitais que pudessem contemplar conteúdos como cores e números, por exemplo. A observadora, juntamente com a professora da turma, fez a seleção dos mesmos. Desta maneira, a primeira análise foi com relação ao conteúdo. Deveria conter ludicidade, pois as crianças gostam de animações e percebeu-se a importância de trabalhar as cores e a pronúncia em inglês visto que a maioria delas ainda possui dificuldades em assimilá-las.

Assim, foi selecionado um jogo sobre cores em inglês. A criança deveria clicar no urso que aparecesse com a cor correspondente na legenda. Utilizou-se o novo aparato tecnológico, óculos de realidade virtual com aplicativo em três dimensões. Outro jogo jogo envolvendo a pronúncia das letras do alfabeto em inglês do ursinho Poof também foi selecionado. Além disso, fez-se uso Quivervision ${ }^{1}$ que é um aplicativo para colorir com personagem em 3D e que usa recursos de realidade aumentada com o celular.

Em sequência analisou-se de que modo os jogos digitais educacionais poderiam representar um acréscimo à aprendizagem significativa de vocabulário. Por fim,

\footnotetext{
${ }^{1}$ Disponível em: https:///www.quivervision.com/
} 
VIII Congresso Brasileiro de Informática na Educação (CBIE 2019)

Anais do XXV Workshop de Informática na Escola (WIE 2019)

buscou-se apontar quais estratégias mais adequadas e utilizadas em laboratório de informática bem como qual foi a receptividade dos alunos com relação à nova metodologia.

As atividades foram realizadas no laboratório de informática da escola seguindo o Plano de Aula elaborado. No início, a professora organizou os alunos e teve uma conversa com eles a respeito de novas tecnologias na sala de aula e sobre o que eles pensavam sobre realidade virtual e sobre jogos em inglês. Logo em seguida, já foi comentado sobre o assunto e perguntado se os alunos lembravam das cores em inglês e assim foi mencionando-as.

Pelo número de alunos em relação a quantidade de recursos disponíveis, concomitante a primeira atividade (jogo eletrônico no computador) foi disponibilizado o jogo de realidade virtual com a utilização do óculos $B O B O V R Z 4$ onde os alunos foram alternando-se no uso e na experiência. Ao final, inseriu-se a atividade de realidade aumentada com a utilização do QuiverVision.

\section{Resultados e discussão}

Percebe-se que o professor deve organizar antecipadamente suas aulas, pois o preparo das atividades e o plano de ensino precisam ser estabelecidos pelo docente com antecipação da aplicação. Mais do que pensar na metodologia e aplicação, é de suma importância pensar em como é feita a avaliação. Dessa forma, o trabalho desenvolvido pela professora obteve um olhar diferente sobre o desenvolvimento, aplicação e avaliação. Olhar esse, que possibilitou discussões e troca de ideias com a observadora. Além disso, foi argumentado com a mesma sobre como seria a duração da atividade e de que forma a experiência prenderia a atenção dos alunos, fazendo com que eles se sintam engajados na atividade.

Levando em consideração os critérios de uma avaliação, o jogo sobre cores, disponibiliza a quantidade de erros e acertos do jogo. Outro critério era a análise e observação das respostas dos alunos com relação às perguntas que iam aparecendo durante a atividade, bem como: a curiosidade de cada participante.

A escolha dos jogos, assim como o processo de avaliação, levou em consideração o perfil da turma e dos alunos. Por isso é tão importante refletir sobre as práticas abordadas na sala de aula bem como os critérios de avaliação. Não se pode avaliar o aluno somente por aquilo que é proposto, deve-se avaliá-lo como um todo (comportamento, interação, participação, interesse e assiduidade) entre outros.

O professor como investigador é capaz de proporcionar ambientes de curiosidade aos alunos. Além disso, as práticas pedagógicas educacionais terão mais sentido se levantadas hipóteses e problematizações a serem solucionadas pelos estudantes. O educador precisa aguçar o gosto por novas aprendizagens e despertar momentos de troca de informações e de criatividade nos alunos. Que sentido teria a pesquisa se estudássemos a mesma coisa todos os dias? Por isso, despertar novas descobertas pela ciência é tão importante como desenvolver o gosto pela leitura. É ensinar o protagonismo infantil.

Para Rodrigues (2013, p. 18) a investigação surge de uma pergunta, de uma adversidade a certo campo de conhecimento. A investigação temática, muitas vezes é uma dificuldade para o docente e o estudante, que se sentem constrangidos em procurar soluções corretas e ágeis. 
Tanto pesquisa, quanto jogos possuem problemáticas a serem resolvidas e desafios a serem enfrentados. Além disso, despertam algum tipo de emoção ou sentimento. Krajden (2017, p. 72), menciona que os jogos são capazes de levar algum tipo de sensação enorme ao prazer mais ousado, passando por sentimentos como impressões de habilidade, vitória e persistência.

Observou-se a motivação das crianças quanto a prática das atividades no computador, pois o game online demonstrava a quantidade de erros e acertos de cada participante. A professora ia elogiando os acertos e os alunos iam se motivando era notável. O papel do feedback nas atividades é fundamental para o progresso dos alunos durante o game. Porém o jogo não mostrava para os alunos onde os alunos tinham errado. Comparando com outros jogos online o feedback é mais rápido: os jogadores passam a ter visão mais clara durante o jogo.

Por fim, é perceptível que as crianças e os adultos quando engajados nas atividades que envolvem motivação, ambos desenvolvem melhor capacidade de concentração. Tanto os games como a gamificação surgiu para desenvolver as habilidades dos indivíduos e estimular no processo do desenvolvimento pessoal. Nesse sentido, pode-se observar que as atividades realizadas durante a experiência com os alunos, oportunizaram, melhor contato com as tecnologias estimulando-as e incentivando-as a conhecer mais sobre a língua e sobre o mundo da realidade virtual como, o dos games.

\section{Considerações finais}

O presente estudo mostrou a importância que o jogo representa não só como uma brincadeira, mas como uma importante ferramenta de ensino, uma nova possibilidade de aprendizagem proporcionando aos alunos momentos de lazer e entretenimento. Nesta experiência houve interesse por grande parte do grupo. $\mathrm{O}$ grupo escolar, assim como o sistema, precisa acompanhar e ofertar a evolução dos alunos por meio do uso da tecnologia.

Ao refletir sobre o período de experiência e realização das atividades, vê-se a importância de estudar e se aprofundar mais sobre o uso das tecnologias na sala e como pesquisa estudar mais sobre Educação Imersiva envolvendo os games voltados a Língua Inglesa. Em vista disso, é preciso repensar a postura profissional, torna-se evidente que os professores são eficazes e primordiais na construção do ensino de qualidade, visto que o aluno constrói conhecimento com base naquilo que é ofertado e naquilo que atribui significado, ou seja, onde encontra motivação. Nesse sentido, Mattar (2010, p. XIII) afirma que o aprendizado necessita de motivação para um envolvimento intenso, o que é atingido pelos games". Além de se estar na era da informação e da comunicação, as crianças têm mais facilidade, pois, muitas já têm acesso a celulares, notebooks, tablets e outros aparatos tecnológicos. E aqueles que não têm, torna-se uma novidade.

Pensando de modo crítico, a criança, ao entrar em contato com a tecnologia, descobre e desenvolve a agilidade digital e, muitas vezes, ensina e auxilia até mesmo os seus avós. Em contraste com a aprendizagem, na qual ela precisa de um adulto para aprender a ler e a escrever, ao aprender a usar o telefone, ela consegue fazer de forma intuitiva. Assim, o docente precisa adotar uma postura investigativa e refletir diariamente sobre a sua postura como profissional em sala de aula. Nenhum 
aprendizado ocorre no modo automático, sem pensar e refletir sobre as práticas e isto, vale tanto para um como para o outro em relação à tomada de decisões.

Além disso, utilizar as tecnologias de forma consciente, ou seja, com preparo, com organização do plano pedagógico e com organização dos conteúdos, é a tarefa inicial do docente, mas se sabe que, no ambiente escolar, existem diferentes "estilos" de professores, conforme se observa. Observou-se que a experiência realizada na escola com jogo online e inserção de óculos de realidade virtual, foi bastante satisfatória. A escola em si, mostrou-se bem receptiva com as novas abordagens de ensino oportunizadas em laboratório.

O ensino do inglês não é mais visto como antes: uma língua distante baseada no ensino de gramática e tradução, mas sim em um contexto social. Sendo assim, a nova Base Nacional Curricular Comum (Brasil, 2018) considera a aprendizagem de inglês uma ferramenta de comunicação no ambiente globalizado. A escola precisa estimular o desenvolvimento das quatro habilidades: ouvir, falar, ler e escrever, além disso, o aluno deve ser capaz de compreender o porquê este idioma é importante.

É imprescindível destacar que deve haver uma mudança na educação, tanto por parte dos professores como por parte dos alunos porque mais do que pensar em tecnologias educativas o que acontece, nas salas de aula, reflete diretamente na qualidade do ensino. O professor e o aluno devem ser protagonistas, aprendendo em conjunto, pois o mundo está em constante evolução, e o conhecimento é algo que precisa ser almejado todos os dias.

\section{Referências}

Brasil. Ministério da Educação (2018). "Base Nacional Comum Curricular". Secretaria de Educação Básica. Brasília.

Krajden, M. (2017) "O despertar da gamificação corporativa". São Paulo. InterSaberes.

Mattar, J. (2010) "Games em educação: como os nativos digitais aprendem". São Paulo: Pearson Prentice Hall.

Rodrigues, A. C (2013). "Pesquisa: O aluno da educação infantil e dos anos iniciais". Ana Cristina da Silva Rodrigues, Nara Eunice Nomberg. Curitiba.

Vygotsky, L. S. (2010) "Aprendizagem e desenvolvimento na Idade Escolar". In: Linguagem, desenvolvimento e aprendizagem. Vygotsky, L. Luria, A. Leontiev, A.N. 11 a Edição. São Paulo: Ícone. 